\title{
Does faith matter? Exploring the emerging value and tensions ascribed to faith identity in South African faith-based organisations
}

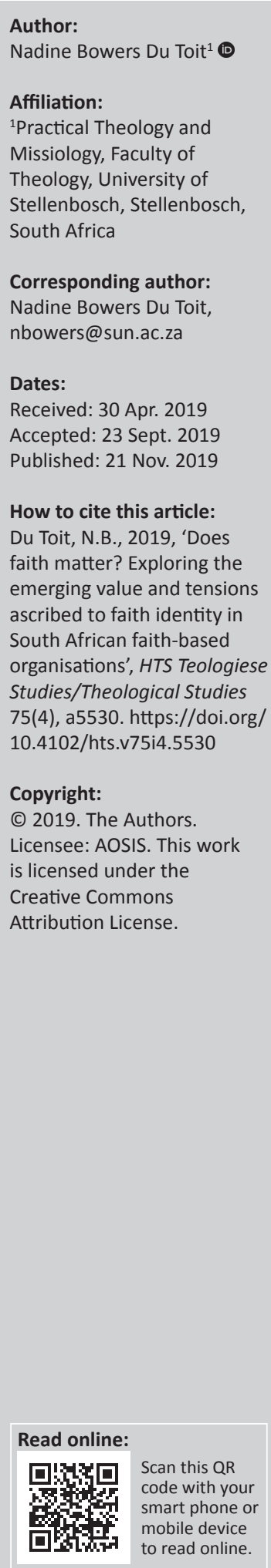

Faith-based Organisations (FBOs) have been at the forefront of a growing interest of the intersection between religion and development. Their value has been recognised as both pragmatic (such as reaching the poorest at the grassroots level and encouraging civil society and advocacy) and, perhaps more contentiously, also 'spiritual' in nature because of advantages arising from faith itself (such as hope, meaning, purpose and transcendental power). For many FBOs, religion is far more than an 'essential component of identity ... it is a source of wellbeing'. In this manner, FBOs challenge the modernist assumptions of traditional development theory, which view the spiritual and physical domains as separate. In fact, for some FBOs, 'spiritual faith provides the fuel for action'. This paper reports on an aspect of the empirical findings of a South African study and explores both the way in which Christian FBOs understand their Christian identity and the way in which they articulate this through their use of scripture as a motivating or an envisioning tool.

Keywords: Faith-based organisations; Development and religion; Faith identity; Integral mission; Non-governmental organisations; Religious identity.

\section{Introduction ${ }^{1}$}

Although research with regard to Faith-based Organisations (FBOs) ${ }^{2}$ has been on the increase, its agenda has been modest in comparison with research of other secular, Non-government Organisations (NGOs) or multi-lateral agencies, and there remains a 'significant gap in our knowledge of FBOs on the ground' (Ohlsen 2008:393; Tadros 2011:67).

Within a South African context, this is even more evident with regard to a lack of comprehensive research on the current and potential role of FBOs within a broader South African context, which are better reflected in other international studies. Faith-based organisations remained, despite the role played by colonial era missionaries in establishing philanthropic organisations and the role of NGOs, ${ }^{3}$ of which most FBOs in South Africa form a part, of utmost importance in providing alternative social services to the majority black population during the apartheid era. It is also in addition to their current role in addressing a range of socio-economic challenges within our country, often working at the coalface of poverty and inequality in South Africa by serving the poorest and the most vulnerable members of our society (Patel 2012:610, 616; Xaba 2016:5).

According to Moyer et al. (2011:24), 'given the increasing role that FBOs are playing within the sustainability arena, understanding how they work and what drives them is becoming ever more important.'

While they share many of the attributes, strengths and weaknesses of secular NGOs, 'FBOs are motivated by a distinctive set of values, have particular modes of operation and hold a unique place within communities and the larger society' (Sider \& Unrah 2004). In a South African context, Swart and Van Der Merwe (2010) noted a similar need:

[T] he identity of FBO's should be considered as central to the ongoing debate about the place and role of the religious sector in the sphere of social welfare and social development in South Africa. (p. 75)

1.It should be noted that this article forms part of a National Research Foundation (NRF) Competitive Unrated Grant (CSUR150623120252 -9918) entitled: 'Does faith matter?' Exploring the role of faith-based organisations as civil society actors. The opinions, findings and conclusions or recommendations expressed in this article are that of the researchers.

2.Please note that the nature of FBOs discussed in this study is described under the methodology section.

3.'A non-governmental organization is not-for-profit, voluntary citizens group, which is organized on a local, national or international level to address issues in support of the common good' (Noor \& Nawi 2016:15)

Note: Faith-Based Organisations, sub-edited by Nadine Bouwers du Toit (Stellenbosch University), Vhumani Magezi (North-West University) and Elisabet le Roux (Stellenbosch University). 
Nevertheless, there is little written on the faith identity of FBOs within the South African context and less still on the manner in which FBOs at the grassroots level understand their own faith identity as faith-based actors within this context. The identity of the FBO within the South African context is, therefore, the focus of this paper, with a particular emphasis on exploring the manner in which Christian FBOs understand the role of their faith - as expressed by FBO workers themselves - in shaping their vision and praxis ${ }^{4}$. The paper utilises both the literature emerging around the value and tensions ascribed to religious identity within FBOs as well as empirical data based on self-reflection by Christian FBO leaders themselves, within the Cape Metropole of the Western Cape, with regard to what they understand as to what it means to be a Christian organisation as well as the role of Scripture in framing their understanding of their work within this context.

\section{Religious identity - Value and tensions}

The increased interest in faith-based NGOs has also resulted in an increase in the corresponding interest with regard to the way in which FBOs' religious identity shapes their work. ${ }^{5}$ Berger (2003:19) notes that unlike NGOs whose starting point is often rights-based, religious NGOs are driven by the 'duty orientated language of religion characterised by obligations toward the divine and others, by a belief in transformative capacities, and a concern for justice and reconciliation'. Occhipinti (2015:336) highlights the fact that for many organisations, and the individuals that work for them, development work is viewed as the way in which they 'live out their faith' as a 'good person in the world'. The findings of Berger's study of a range of FBOs from various religious traditions affirms the notion that the services provided by FBOs and the manner in which the services are rendered is deeply based on their religious beliefs and are viewed as 'a practical expression of their religious beliefs' attached to what they consider a calling 'to be a positive change in society' (Berger 2003:32).

In order to begin to explore the religious nature of FBOs, some scholars have produced typologies of religious characteristics of such organisations in order to capture the nature of their religious identity (Clarke \& Jennings 2008; Sider \& Unrah 2004). In Sider and Unrah's (2004) study, six different 'types' of organisations, based on their religious dimensions, were identified, namely, faithpermeated, faith-centred, faith-affiliated, background faith, secular partnerships or secular. Hefferan et al. (in Leurs 2012:707) on the other hand assesses the 'manifestations of faith in individual organisations in order to place them along a secular to faith spectrum'.

\footnotetext{
4.The broader project from which this article is drawn attempts to do exactly that and seeks to explore the current and potential role of Faith-based Organisation (FBOs) for transformation in South Africa.

5.The issue of defining Christian identity particularly is a contested one, owing to the fact that spirituality and worship differ widely and the fact that Christian identity is dependent on context (Mostert 2008:51)
}

Key organisational features include (Hefferan in Leurs 2012):

[S]elf-description as faith-based or secular, identity of the founder and organisers, identity of the managers and leaders, religious affiliation of the staff and volunteers, sources of financial and other support, organised faith practices of staff and volunteers, the faith content of the programmes, the main way faith is integrated with other programme features, expected connections between faith content and programme features and the use of faith symbols. (p. 707)

Clarke identifies FBOs as falling into categories such as passive (faith plays a 'secondary role to humanitarian considerations'), active (no overt discrimination, but faith as an explicit motivation), persuasive (faith is explicit and the dominant basis for engagement and focusses on evangelism) and exclusive (it is the 'principle of sole consideration in identifying beneficiaries and is rooted in faith linked to militant or violent social and political engagement') (Noor \& Nawi 2016:22). These typologies appear to indicate that FBOs are diverse in the way in which they self-understand their work and role and could also be viewed as linked to the manner in which they use faith to mobilise staff and supporters (Occhipinti 2015:337).

Ware, Ware and Clarke (2016:322) make the point that the faith base of FBOs has both been linked to a 'range of beneficial outcomes' in some contexts and 'induced negative outcomes' in other contexts. In Ware et al.'s (2016:323) literature review of grey literature regarding the impact of faith, they suggest that 'FBO's empower people in a way that brings personal dignity, self-worth and contentedness, which in turn bring hope and vision'. They also note that indigenous FBOs in particular are more sensitive to local cultural and religious contexts and are, therefore, 'able to tailor their organisational styles and activities' to those contexts (cf. James 2011:111; Lunn 2009). Other scholars highlight their long-term presence and networks in communities, which promote trust and moral authority, as well as a unique commitment and motivation based on their religious convictions to serve (Occhipinti 2015:332, cf. Tadros 2011:65). Perhaps, most interesting is the following:

Faith is said to shape an FBO's structure, activities and outcomes, even providing an alternative to more secular theories of development (Para-Mellam 2006; Lunn 2009; Aiken 2010:6). For example, many FBO's view poverty as having spiritual components that need to be addressed to most effectively improve material circumstances (Clarke 2007). However, other authors claim that faith is linked to promotion of idealised types of the poor and needy leading to limited engagement with the community's perception of needs. (Bradley 2015) Likewise, some FBO's use relief and development to proselytise (Bradley 2005), although it should be noted that even where FBO's do engage in proselytization, the literature argues anecdotally that poverty alleviation remains an integral and equally important element in their motivation. (Dilger 2009:99-100; Ware et al. 2013, 2016)

James (2011:111, 112) also highlights several of the same issues. He warns of the danger, for example, of FBOs using their own control over resources to manipulate people to convert to their faith; however, he also notes the advantages 
that faith offers through spiritual teaching and through providing 'hope, meaning, purpose and transcendental power' as well as the alternative to secular development theory that they provide. The latter is especially important in global South contexts where there is often no distinction between the material and the spiritual realms. Development that only addresses the material, therefore, is at a distinct disadvantage in addressing behaviours and values that perpetuate these issues. Furthermore, in such contexts, faith is often expected to engage the public realm from the very perspective of faith, unlike European contexts where faith may be perceived as firmly positioned within the personal or private domain (James 2009:10; Thaut 2009:320). In this way, FBOs are contesting the neo-liberal notion of development in 'offering alternative visions of morality and what it means to live a good life' (Tomalin 2015:333).

James (2011:112-113) notes the ways in which spiritual teaching plays a key role in reinforcing development principles such as justice, compassion, care and environmental care, and lists several additional benefits such as, namely, long-term presence in communities, legitimacy in the eyes of the poorest, efficiency of development services, promotion of volunteerism and the encouragement of civil society advocacy. A Nigerian study on the faith identity of FBOs highlights the centrality of religious values and practices in an African context. In this study, religious values were central to the way in which programmes were designed, implemented and evaluated, and religious activities such as services or prayer were also central to their programmes (Leurs 2012:714). The study also found that 'all the FBO's studied deliberately recruited staff and board members from their faith tradition', while nevertheless serving beneficiaries from other faiths.

Furthermore, it should be noted that for many FBOs, 'spiritual faith provides the fuel for action' and, therefore, 'the point at which this becomes proselytising is not always clear' (James 2011:115). The latter is certainly a point of tension as highlighted by the aforementioned Nigerian study, where some FBOs saw their responsibility to evangelise as closely tied to their work - and even as an ultimate means to proselytisation (Leurs 2012:713). This is not unusual as for 'FBO staff and organisations, faith underlies and connects all of their activities' (Occhipinti 2015:341).

Another issue, which pertains directly to affecting the faith identity of FBOs, is that of donor funding.

Sinha's (2012:576) study appeared to indicate that organisations that identified as more evangelical and saw their 'service provision as a direct expression of obedience to a higher authority that, for some organisations, presents a conflict to accepting government grants or contracts'. Furthermore, Thaut (2009:329) cites several studies that show that there is 'a negative relationship' between religiosity and government or other forms of secular funding, which often leads to 'mission creep'. This means that the original goals and values of the programme or organisation are bent or altered to secure state or other secular funding. Furthermore, where FBOs are aligned to larger, secular umbrella organisations, ${ }^{6}$ FBOs are more likely to succumb to the loss of their religious identity and founding faith community (Wittberg 2012:559).

\section{Methodology}

The findings explored in this paper originate from a larger study, entitled: 'Does faith matter? Exploring the role of faithbased organisations as civil society actors'. This study was conducted between January 2016 and March 2018, and sought to explore the current and potential role of FBOs for transformation in South Africa. Among other questions, the study sought to investigate the value ascribed to Christian theology, ethics and beliefs in shaping FBO practice, and this paper, therefore, focusses on this aspect, as it is reflected in an electronic survey sent to $80 \mathrm{FBO}$ in the Cape Metropole (Western Cape Province, South Africa).

Figure 1 depicts the spread of organisations that responded to the survey according to areas within the Cape Metropole.

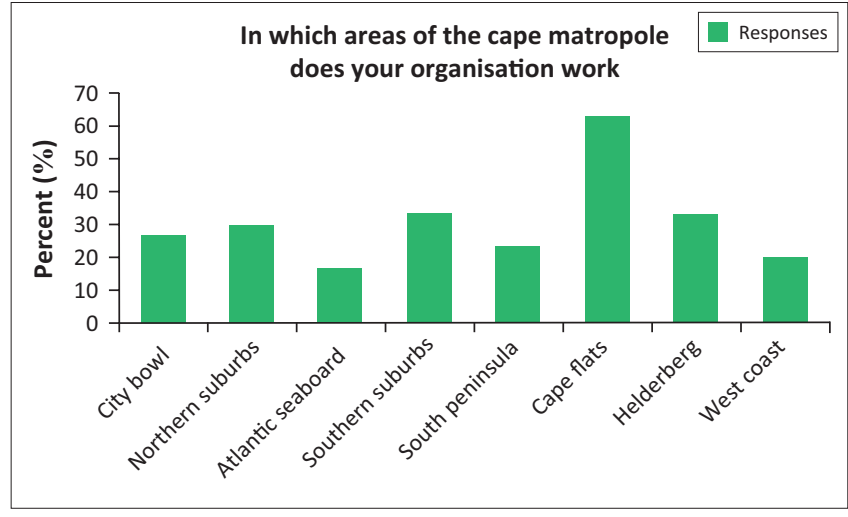

FIGURE 1: Graph of distribution of faith-based organisations surveyed within the Metropole.

With reference to Figure 1, it should be noted that it is not surprising that the majority of FBOs are based in the Cape Flats, as this is the poorest part of the Metropole and arose out of apartheid planning, which pushed people of mixed race to the margins of the metro.

Within the project, we have chosen to identify organisations who either self-identify as faith based or have been identified as such by affiliation to faith-based networking bodies. Furthermore, for the purposes of this study, we have limited our understanding of FBO to be locally or grassroots based, development focussed and formally registered organisations. In this way, the organisations we have included in the study are all recognised legal entities such as nonprofit organisations, trusts and public benefit organisations, but do not include the more informal Community-based Organisations (CBOs) or congregations, denominations, 6.This refers to non-profit organisations whose members themselves are non-profits (Wittberg 2012:542). 
missionary groups and educational institutions, which may be included in broader definitions. The study also limits the scope of FBOs to those of the Christian faith. In addition, it should be noted that the study is explorative in nature as no study of this kind has been conducted in South Africa. Four databases were utilised stemming from two FBO networks, a locally based donor organisation who largely funds FBOs in the Cape Metropole and an online data base of Christian organisations. The survey was sent to 80 organisations in total situated in Cape Metropole from these databases. Snowball sampling was then utilised in identifying additional organisations by including a request for 'leads' on the electronic survey itself". Forty-two FBOs responded to the survey, which was targeted at the level of organisational leaders. The survey was conducted electronically using Survey Monkey, and ethical clearance was provided.

This paper reports on the empirical findings drawn from two open-ended questions in the survey with regard to faith identity, and thematic coding was utilised to code these open responses. Two specific responses are coded, namely: 'What is the meaning of a Christian Organisation?' and 'is there any bible story or verse that motivates your work?' The former was an open question intended to better understand the way in which Christian FBOs view and even embody their faith identity. The second question intended, firstly, to gauge whether the scared text of Christianity played any role in their work and then the kind of biblical texts that are used in supporting their faith identity. All organisations are anonymised through the allocation of codes.

\section{Findings \\ Meaning of a Christian organisation}

Out of 42 organisations that responded to the survey, 35 responded to the question: 'What is the meaning of a Christian organisation?' The reasons for non-response could be interpreted in several ways: Either respondents had no time to answer open-ended questions or they felt they had little relevance. Berger's (2003:19) and Occhipinti's (2015:336) views that FBOs are inherently driven by their faith and worldview, rather than by a right-based starting point, is confirmed by the data. Over half of the organisations noted that this meant that the Christian faith shaped their vision, ethos or values: 'It is what defines our morals, values, goals and vision' (P2) or 'Living out our Christian ethos in our everyday lives' (P25) and 'Christian faith underpins our values and direction as an organisation' (P28) among other similar responses.

Not only is their Christian faith seen as shaping vision and ethos, but it is also seen as a core motivation in the work that they do: Giving 'purpose to what we do' (P2), 'it is at the core of what we do' (P34), 'the foundation of what we do' (P40) or 'we are believers in Christ. He is the motivation for what we do' (P19), and even when they are not openly identified as

7 The survey was piloted with 10 FBOs in Stellenbosch, - an area which falls outside of the Cape Metropole - prior to being sent out. faith based, one organisation noted that 'we are motivated to do the work we do because of our faith in Christ' (P5). Another talked about 'gospel motivated social action' (P8) and some noted that they believed that it is only through Jesus Christ that clients' or recipients' problems can truly be addressed (P8, P10). Many of these organisations could therefore sit closer to Sider and Unrah's (2004) faith permeated, centred and affiliated typologies than those with background faith, secular partnerships or that are secular.

The issue of evangelism of proselytisation also clearly arises from the data and also highlights the complex ways in which the notion of witness is broader than these terms (and their often-negative associations) and do not always imply a heavy-handed type of conversion as an end of development work. The theme of Christian witness arises quite a few times, which ranges from those in the community 'seeing the difference in the way you live, work and operate' (P41), 'propagating and demonstrating the Christian faith' (P37), 'being a good example to lead people to Jesus' (P10) and 'to being light where there is darkness' (P39). The latter appears to infer that proselytisation is a key component of the work of some of the FBOs; however, although some responded that while Christian values, ethos and even teaching both underpin and may be overtly mentioned and integrated in their programmes, they do not discriminate in terms of who they serve as clients or recipients (P27, P28, P5, P8, P32). The centrality of Christian witness appears to be largely founded on the notion that spirituality must be integrated in the work they do and for this reason some noted that employees, board members - and for some even volunteers - must be professing Christians (P28, P27, P36, P32). For those who are founded as part of a local church's 'outreach' work, such as P14, this would also be a given. Interestingly enough, these findings echo the aforementioned Nigerian study, which also found that many organisations recruited religious staff and board members (Leurs 2012).

This is in turn founded on an understanding that organisations make little division between the material and spiritual realms and see both proclamation of the gospel (which secular thinkers term proselytisation) and its demonstration through acts of charity and development as two sides of the same coin (P23). It should be noted that in this way they see witness as indivisible. Their faith drives them to 'take seriously the reality of the unseen realm and that all our work is spiritual' (P30). These views, indeed, support the notion that development - particularly in a Global South context contests neo-liberal notions of development and indeed promotes a holistic ${ }^{8}$ approach to the gospel within the Christian faith.

In a similar way to the Nigerian study, there is a definite call to take spirituality seriously, and many of them emphasised integration of faith in their practices, teachings and programmes. One noted that faith 'forms the foundation of

8.Holistic refers to equal consideration being given to the material and spiritual components. 
what we do. It is integral to our approach, our material and our outcome' (P40). Such integration is not true of all respondents and there are clearly different ways in which faith finds its way into the manner in which these organisations operate. This ranged from teaching Christian values and ethos - also through attitudes and approaches (P27, P29, P18, P21, P22, P40, P20, P33, P35, P36), to creating 'space for faith being integrated in our day to day practices and long term strategy' (P30) through spiritual practices such as prayer and scriptures (P18, P27, P32), through their programme materials (P40, P22, P27) and through their witness within the communities which they serve as aforementioned (P36, P22, P20, P29, P38).

\section{Use of scripture}

Although a minority did not respond to the question, the responses that were captured are interesting and reflect the manner in which organisations are motivated or envisioned by the biblical text. This indicates that many of these organisations frame their work in terms of the biblical text and even have particular scriptures that they frame their work around, which perhaps points to the role of the biblical text in their self-understanding. For these findings, the researcher took the passage noted - looked up the actual verse/verses and then analysed the compiled list of verses thematically. Four key themes emerged, namely, justice, restoration, compassionate witness and hope/meaning/purpose. The strongest theme is that of compassionate witness.

Two respondents used 2 Corinthians 2:14 in which 'Christ's love compels us', which could be interpreted as a call to compassionate action. Another text cited simply calls the reader to 'comfort, comfort my people, says your God' (Is 40:1) - perhaps another call for the compassionate action of comfort.

Others cited stories from the Synoptic gospels provided Jesus as an example of compassion to those who are marginalised by society (Matt $14: 14 ; 5: 14-16$ ) or his disciples who have acted in this way (Ac 3:1-7). Jesus' feeding of the 5000 was also cited - perhaps indicating that Christ dealt holistically with the needs of people. This is also expressed through the most well-known scriptural injunction to 'love thy neighbour' (Matt 22:37-39). The theme of love of neighbour and Christ as compelling them to action or Christ as the ultimate example of what interaction with the marginalised should look like can certainly be interpreted in the light of Berger's (2003:19) point of FBOs being driven by 'duty orientated language' to care, love and show compassion.

Berger (2003:19) also noted that this is linked to a concern for justice and reconciliation. The theme of justice came through most strongly from prophetic texts such as Isaiah and Micah, although Psalm 12:5, which also has a strong justice focus is mentioned: 'because the poor are plundered and the needy groan, I will now arise, says the Lord. I will protect them from those who malign them', as this text indicates that God himself will arise to defend the poor and the needy as they are subjected to injustice. Isaiah 61 - which Jesus uses to announce his public ministry in Luke 4:17-19 - was mentioned by three respondents as their foundational text. This text clearly refers to 'good news to the poor', 'freedom for the captives' and refers to release from oppression and marginalisation. It also refers to the 'Year of the Lords favour' - a Year of Jubilee where all things will be restored and justice will reign. Micah 6, another prominent justice text, was also mentioned:

He has shown you, O mortal, what is good. And what does the Lord require of you? To act justly and to love mercy and to walk humbly with your God. (v.8)

The latter clearly integrates spirituality with just actions. These prophetic texts were often also highlighting the theme of restoration or rebuilding. It is perhaps not unsurprising that respondents chose such texts in a nation, which is still rebuilding after the devastation of apartheid, which left us with high rates of poverty and race-based inequality and high levels of abuse of women and children. Isaiah 61: 4: 'they will rebuild the ancient ruins and restore the places long devastated' or Isaiah 58:11-12 'your people will rebuild the ancient ruins... you will be called Repairer of Broken Walls Restorer of Streets with Dwellings' (see also 2 Chr 7:4-15). These texts also certainly point to the desire of FBOs and their leaders to be a force for change in society as previously noted in the literature review.

Their identification of the need to counter a dichotomy between the spiritual and material realms is not only identified in the findings from the previous section but also by the kind of biblical texts chosen which emphasise this. An understanding of witness as holistic, for example, is picked up by other texts that are sighted, such as 'let your light shine before others, that they may see your good works and praise your father in heaven' or Ephesians 2:10 in which Christians are reminded that they are 'created in Christ Jesus to do good works'. These texts counter the notion that salvation is only spiritual. One organisation chose a text, which warns that true and pure religion in God's eyes is one that 'looks after widows and orphans in distress' (James 3), thus emphasising God's heart for the marginalised in society, which also possibly connects with the target groups of this organisation. Another organisation cited both the 'great commandment' (love thy neighbour) together with the 'great commission' (to convert and make disciples), which may also indicate that they see the two as inseparable or the gospel as holistic in nature.

What is perhaps most surprising is the fact that Jeremiah 29 is mentioned by three respondents and in reading the text, it does not appear to have any immediate relevance to the work of development:

'For I know the plans I have for you,' declares the Lord, 'plans to prosper you and not to harm you, plans to give you hope and a future'. Then you will call on me and come and pray to me, and I will listen to you. You will seek me and find me when you seek me with all your heart. I will be found by you. (vv. 11-13)

Reference to this text could be interpreted in several ways. The most obvious interpretation would simply be that this 
text is one which encourages them as an organisation that they will not fail in their mission as God is with them. It could also be interpreted against the context in which many of these organisations are working, namely, with marginalised children/youth and women or offenders and drug addicts. The vulnerable and marginalised often view themselves as unloved and either because of past offences or their vulnerability may feel as if they have no purpose. It is clear that this text refers to the kind of hope, meaning and purpose that James (2009) and Ware, Ware \& Clarke (2016) note as one of the hallmarks in order to help such groups understand their purpose and value. Another interesting text is the one which expressed the understanding that Christ was willing to lay down his life for the ungodly. Some organisations interviewed work with violent offenders who have been released from prison or former drug addicts. It cannot be confirmed, but the inference here may be that they are called to this work - even those who are considered 'ungodly' or of morally questionable behaviour deserve Christ's mercy and therefore the call to work with them.

\section{Conclusions}

It is clear that faith is a core motivator for the work that South African FBOs do and influences the manner in which they do it - whether it is through their vision, organisational structures, programmes or the kinds of people they employ or use as volunteers. In fact, as noted in the findings, the majority of the organisations that responded to the survey recognise faith as central to their work and scriptures as foundational to their identity. The spiritual values noted by James and Berger (such as compassion, justice and reconciliation) are evident in the way $\mathrm{FBOs}$ frame their understanding of a Christian organisation, as well as the scriptural references to these values as core themes. What is even more interesting is the fact that Ware et al.'s claim 'FBOs empower people in a way that brings personal dignity, selfworth and contentedness, which in turn bring hope and vision' is affirmed by FBOs' self-understanding through their use of biblical texts such as Jeremiah 29. Texts, which may otherwise be seen as more obscure than standard justice or compassion texts when dealing with development. It is also clear that many of the FBOs, indeed, make no differentiation between spiritual and material activities, and that while this may have positive benefits in some respects, it also raises questions around proselytisation. Even from within the Christian faith, it is theologically understood that although both are seen as part of the gospel, development and welfare work should not be used as a means for proselytisation. Perhaps, to some in more secular Western contexts, these findings may be shocking, or perhaps even undesirable; however, what the findings do reveal is that FBOs in the Cape Metropole see themselves as just that - faith based.

\section{Acknowledgements}

This article forms part of a National Research Foundation (NRF) Competitive Unrated Grant (CSUR150623120252 9918) project entitled: 'Does faith matter?' Exploring the role of faith-based organisations as civil society actors. The opinions, findings and conclusions or recommendations expressed in this article are that of the researcher.

\section{Competing interests}

The author declares that they have no financial or personal relationships which may have inappropriately influenced them in writing this article.

\section{Author's contributions}

N.B.D.T. is the sole author of this research article.

\section{Ethical considerations}

The article followed all ethical standards as stipulated by Stellenbosch University and acquired ethical approval from said institution (ethical clearance number: SU-HSD-003625).

\section{Funding information}

This research received funding from the NRF as part of the project: 'Does faith matter?' Exploring the role of faith-based organisations as civil society actors.

\section{Data availability statement}

The author confirms that the data supporting the findings of this study are available within the article and/or its supplementary materials.

\section{Disclaimer}

The views and opinions expressed in this article are those of the author and do not necessarily reflect the official policy or position of any affiliated agency or author.

\section{References}

Berger, J., 2003, 'Religious nongovernmental organisations: An exploratory analysis', Voluntas 14(1), 15-39. https://doi.org/10.1023/A:1022988804887

Clarke, G. \& Jennings, M. (eds.), 2008, Development, civil society and faith-based organizations: Bridging the sacred and the secular, Palgrave Macmillan, Hampshire.

James, R., 2009, What is distinctive about FBOs? How European FBOs define and operationalise their faith, Praxis paper 22, INTRAC, Oxford.

James, R., 2011, 'Handle with care: Engaging with faith-based organisations in development', Development in Practice 21(1), 109-117. https://doi.org/10.1080/ 09614524.2011.530231

Leurs, R., 2012, 'Are faith-based organisations distinctive? Comparing religious and secular NGOs in Nigeria', Development in Practice 22(5-6), 704-720. https://doi org/10.1080/09614524.2012.685868

Lunn, J., 2009, 'The role of religion, spirituality and faith in development: A critical theory approach', Third World Quarterly 30(5), 937-951. https://doi.org/ 10.1080/01436590902959180

Mostert, C., 2008,'Identity as baptismal identity', in E. Van der Borght (ed.), Christian Identity, pp. 51-65, Leiden, Brill.

Moyer, J.M., Sinclair, J.A. \& Spaling, H., 2011, 'Working for God and sustainability: The activities of faith-based organizations in Kenya', Voluntas, December, $1-34$.

Noor, A.L. \& Nawi, N.H., 2016, 'Faith-Based Organisations (FBO): A review of literature on their nature and contrasting identities with NGO in community development intervention', European Journal of Economics and Business Studies 4(1), 14-28. intervention', European Journal of Economics
https://doi.org/10.26417/ejes.v4i1.p14-28

Occhipinti, L., 2015, 'Faith-based organisations and development', in E. Tomalin (ed.), The Routledge handbook of religions and global development, pp. 331-345, Routledge, New York, NY 
Ohlson, E., 2008, 'Common belief, contested meanings: Development and faith-based organisational culture', Tijdscrift voor Economische en Sociale Geografie 99(4), 393-405. https://doi.org/10.1111/j.1467-9663.2008.00481.x

Patel, L., 2012, 'Developmental social policy, social welfare services and the non-profit sector in South Africa', Social Policy and Administration 46(6), 603-610. https:// doi.org/10.1111/j.1467-9515.2012.00858.x

Sider, R. \& Unrah, H. 2004, 'Typology of religious characteristics of social service and educational organizations and programs', Non-profit and Voluntary Sector Quarterly 33(1), 109-134. https://doi.org/10.1177/0899764003257494

Sinha, J.W., 2012, 'Unintended consequences of the faith-based initiative: Organisational practices and religious identity within faith-based human service organisations', Nonprofit and Voluntary Sector Quarterly 42(3), 563-583. https://doi.org/ 10.1177/0899764012462457

Swart, I. \& Van der Merwe, W., 2010, 'Towards conceptualising faith-based organisations in the context of social welfare and development in South Africa', in I. Swart, H. Rocher, S. Green \& J. Erasmus (eds.), Religion and social development in post-Apartheid South Africa: Perspective for critical engagement, pp. 75-90, Sun Press, Stellenbosch.
Tadros, M., 2011, 'The faith factor in reimagining development', IDS Bulletin 42(5), 63-67. https://doi.org/10.1111/j.1759-5436.2011.00253.x

Thaut, L., 2009, 'The role of faith in Christin faith-based humanitarian agencies: Constructing the taxonomy', Voluntas 20(4), 319-350. https://doi.org/10.1007/ s11266-009-9098-8

Tomalin, E., 2015, Routledge handbook of religions and global development, Routledge, Abingdon.

Ware, V., Ware, A. \& Clarke, M., 2016, 'Domains of faith impact: How "faith" is perceived to shape faith-based international development organisations', Development in Practice 26(3), 321-333. https://doi.org/10.1080/09614524.201 6.1149150

Wittberg, P.A., 2012, 'Faith-based umbrella organisations: Implications for religious identity', Nonprofit and Voluntary Sector Quarterly 42(3), 540-562. https://doi. org/10.1177/0899764012461954

Xaba, T., 2016, 'From public-private partnerships to private-public stick'em ups! NGOism, neoliberalism, and social development in post-apartheid South Africa', International Social Work 1(1). 